\title{
Personality Characteristics, Locus of Control and Hostility among Alcoholics and Non-Alcoholics
}

\author{
Amandeep Singh (Corresponding author) \\ Department of Psychiatry \\ Sri Guru Ram Das Institute of Medical Sciences \& Research \\ Vallah, Amritsar, Punjab, India \\ Tel: 91-981-494-9794_E-mail: singhaman123@rediffmail.com \\ Dr Davinder Singh \\ Reader, Department of Psychology, Guru Nanak Dev University \\ Amritsar, Punjab, India
}

Received: October 25, $2010 \quad$ Accepted: November 25, 2010 doi:10.5539/ijps.v3n1p99

\begin{abstract}
The present investigation has been undertaken with a view to investigate the personality characteristics, locus of control and hostility among alcoholics and non-alcoholics. The sample consists of 100 alcoholics and 100 non-alcoholics in the age range of 18-30 years. The measures used for this study are Sixteen Personality Factor Questionnaire, Levenson's Locus of control and Covert and Overt Hostility Scale. The results are discussed in terms of comparison of means and discriminant analysis. The result clearly reveals that significant differences were found on personality characteristics, locus of control and hostility between alcoholics and non-alcoholics.
\end{abstract}

Keywords: Personality, Locus of control, Hostility, Alcoholics, Non-alcoholics

\section{Introduction}

Alcoholism refers to dependence on alcohol to the extent that it seriously interferes with life adjustment. An alcoholic is an individual with serious drinking problems, whose drinking behaviour impairs life adjustment in terms of health, personal relationships and / or occupational functioning. According to Jellinek (1960) define alcoholism as a disease and Mello (1972) has explained alcoholism in terms of three attributes of disease like agent, host and environment.

Alcoholism has far reaching effects, not only on the individual experiencing it, but on his immediate family and the society at large. Alcoholics not only develop physiological dependence on alcohol, rather they develop a powerful psychological dependence as well (Carson et al, 2000). Relationship of alcoholism with personality is very complex and it has been generally recognized that there is no one personality pattern shared by all alcoholics (Stacy et al. 1991).

Suman and Nagalaxshmi (1996) used Eysenck personality inventory and family index scale and found that 8 variables are significantly influenced. These include family functioning, emotional problem in children and discrepancy between spouses, role functioning of alcoholism, psychotocism, perception of self, love dimension and neuroticism.

Russel et al. (1997) found relationship between alcoholism and reported two basic determinants of personality i.e. extroversion and neuroticism which play an important role in social network and whereas Starrels (1962) has reported no significant differences between alcoholics and non-alcoholics. Robert et al. (2007) found positive correlation between antisocial personality and alcoholism. Jenny and Klinteberg (2010) reported significant relationship between alcoholism and violent delinquent behaviour.

Alcoholism is also linked to locus of control, which has been defined as a generalized expectancy variable (Rotter 1966). Locus of control is descriptive of individual differences in relatively enduring disposition to perceive 
reinforcement contingencies as either under personal control (internal) or the control related to luck, chance, fate and powerful others (external).

Various researchers have reported external locus of control as an important characteristic of alcoholics (Cormelo \& Demoja 1997, Post et al 1998, Marchiori et al 1999) and many others found that no clear-cut relationship between alcohol abuse and locus of control (Obitz et al 1978, Renuka and Hemraj 1996). Mills (1991, 1992) using Rotter's Internal-External Locus of control scale found that children of alcoholics significantly differed on external locus of control from control group. Huckstadt (1997) studied categorization of alcoholics. In this study there were three groups like non-alcoholics, recorded alcoholics and alcoholics. He found that non alcoholics had more internal locus of control than alcoholic but another study Zungalo (1997) disagreed with the ideas concerning alcoholics control and categorization of alcoholics.

Hostile behavior also plays an important role in alcohol abuse. Many studies found positive relationship between alcoholism and hostile \& aggressive behavior (Baldwin \& Randolph 1982, Rajendran and Cherian 1992, Michel et al 2003, Schumacher et al 2008). Abelsohn and Spuy (1978) reported that significant differences were found in hostility on different stages of ages in alcoholics. Tivis et al. (1998) in their investigation reveal that alcoholics show more aggressive behavior than control group. Ziherl et al (2007) reported that significant relationship between hostility and covert aggression between recovered alcoholics and non-alcoholics after three years abstinence.

In addition some investigators have reported that potential alcoholics tend to be emotionally immature and expect a great deal from the world, require an inordinate amount of praise, react to failure with marked feelings of hurt and inferiority, have low frustration tolerance and feel inadequate and unsure of their abilities. While, such findings provide promising leads, it is difficult to assess the role of personality, locus of control and hostility or environmental factors in the development of alcoholism. Certainly many people with similar characteristics do not become alcoholics and others with dissimilar ones do. The only characteristic that appears to be common to the backgrounds of most problem drinkers is personal maladjustment, yet most maladjusted people do not become alcoholics.

Keeping in mind the contradiction in this existing literature it becomes imperative to do the comparative studies to explain personality characteristics, locus of control and hostility among alcoholics and non-alcoholics. Thus the present study "Personality Characteristics, Locus of Control and Hostility among Alcoholics and Non-Alcoholics" was undertaken with following objectives:

1) To compare the personality characteristics, locus of control and hostility of alcoholic and non-alcoholics.

2) To differentiate the two groups on the basis of discriminant coefficients.

\section{Method}

\subsection{Sample}

The sample consists of 200 male subjects including 100 alcoholics and 100 non-alcoholics. The alcoholics were selected from de-addiction centres and hospitals of Amritsar, Punjab. The age range of subjects was between 18-30 years. The selected sample was more or less homogeneous with regard to middle socio-economic status, cultural background and academic qualification.

\subsection{Measures Used}

\subsubsection{Sixteen Personality Factor Questionnaire (16PF: Cattell, 1969)}

The Sixteen Personality Factor Questionnaire (Form C) developed by Cattell and his associate was used in the present investigation because it has been very frequently used in occupational selection work and clinical setting.

\subsubsection{Locus of Control Scale (LOC: Levenson and Miller, 1976)}

Levenson and Miller (1976) constructed a scale to measure internal-external locus of control. This scale is based on Rotter's scale (1966) and the author in this scale report an internal factor and two components of external dimension i.e. powerful others scale and chance scale.

\subsubsection{Covert-Overt Hostility Scale_(CH-OH: Bendig, 1962)}

Bendig (1962) developed a scale, which is widely used to measure covert and overt hostility. The questionnaire consists of 34 items and each item has two alternatives i.e. True and False. The scale has been designed to access two factorially distinct modes of emotional expression. The modes of emotional expression are covert hostility i.e. indirectly expressing hostile feelings and impulses and overt hostility i.e. aware of openly expressing hostile feelings and impulses. 


\subsubsection{A structural interview Schedule}

In order to assess the emotional behaviour of the subjects a structured interview schedule consisting of 20 items was administered.

\subsection{Procedure}

Preliminary permission was taken from the De-addiction centre and hospitals authorities for conducting this study. Before administering the questionnaires, a good rapport was established with the subjects and they were assured of the confidentially of their responses. A short interview questionnaire was administered separately and then test was administered in group situation with group strength of $4-5$ subjects. The subjects were given instructions as per the respective manuals.

\section{Result and discussion}

\subsection{Reliability}

Reliability coefficients of Sixteen Personality Factor Questionnaire were computed by Kuder-Richardson method (KR-20) which ranges from 0.53 to 0.78 with a mean $r_{t t}$ of 0.63 . Reliability coefficients of Levenson's Locus of Control scale were estimated by test- retest method which came out to be $0.76,0.65$ and 0.61 for the Internal, Powerful others and Chance scale respectively. Finally test-retest reliability coefficients were obtained for Covert and Overt Hostility Scale which came out to be 0.64 and 0.66. Keeping in view the small number of items in the sub tests and the conventional standards, the obtained reliability coefficients seem to be highly satisfactory.

\subsection{Comparison of Means}

In an attempt to investigate the difference among alcoholics and non-alcoholics, the t- test was applied on all the measured variables. The means and standard deviations of all the measured variables along with their t-ratios for the two groups are presented in table 1.

\section{Insert Table 1 about here}

With reference to personality, locus of control and hostility, alcoholics differed significantly from non-alcoholics on 11 accounts namely factor $\mathrm{C}$, factor $\mathrm{E}$, factor F, factor L, factor Q1, factor Q2, factor Q3, internal scale, powerful others, covert hostility and overt hostility i.e. alcoholics scored higher on factor $\mathrm{C}(\mathrm{t}=2.04 ; p<.05)$, factor $\mathrm{E}(\mathrm{t}=3.76 ; p<.01)$, factor $\mathrm{L}(\mathrm{t}=2.40 ; p<.05)$, factor Q3 $(\mathrm{t}=2.60 ; p<.01)$ and overt hostility $(\mathrm{t}=2.20 ; p$ $<.05)$ where as non-alcoholics scored higher on factor $\mathrm{F}(\mathrm{t}=3.32 ; p<.01)$, factor $\mathrm{Q} 1(\mathrm{t}=2.16 ; p<.05)$, factor Q2 $(\mathrm{t}$ $=3.41 ; p<.01)$, covert hostility $(\mathrm{t}=2.84 ; p<.01)$, internal scale $(\mathrm{t}=2.36 ; p<.05)$ and powerful others $(\mathrm{t}=3.20$; $p<.01)$. It means that alcoholics are emotionally more stable, aggressive, suspicious, controlled and less affected by their feelings. Moreover they are more independent minded, self-opinionated, un-concerned about other people, disregard authority and overtly hostile as compared to non-alcoholics where as non-alcoholics are more enthusiastic, experimenting and self sufficient and covertly hostile than alcoholics. The t-test also clearly indicated that non-alcoholics scored higher on internal and powerful others scale than alcoholics.

The results of the structural interview schedule clearly revealed alcoholics suffered more when one of family member was alcoholic and the other non-alcoholic. They suffered less when both the members (i.e. father or son) are alcoholic and non-alcoholic. This may be due to the kind of environment in the family. The alcoholics disclosed that they were least interested in alcohol but they used to be very tense and frustrated when their fathers used to come late night under the influence of liquor. After some time, almost at the same time they also started consuming alcohol and afterwards they remained stable. The results of t-test for other components of personality were non-significant.

\subsection{Discriminant Analysis}

Discriminant function analysis was applied to the two groups of subjects included in the study. The analysis was done with dual purpose of examining the discriminant coefficients of all the variables so as to identify the groups that are best predicted by the different variables under study and also to see the accuracy of classifying the subjects into two different groups on the basis of the obtained results. The results of discriminant analysis are presented in Table 2. The variables along with their discriminant coefficients are arranged in decreasing order in the Table i.e. variable having maximum weight in predicting group membership is placed at the top while variable at the lower end is having minimum weight.

Group I consists of alcoholics whereas Group II is that of non-alcoholics. 
Table 2 indicates that the value of Wilk's Lambda is. 716 which is significant at .000 level thus indicating that the two groups can be significantly discriminated on the personality characteristics, locus of control and hostility variables included in the study.

As far as the classification on the basis of discriminant function score are concerned (See Table 3) in Group I, 74 out of $100(74 \%)$ cases are correctly classified on the basis of the variables. In Group II, 71out of $100(71 \%)$ cases are correctly classified on the basis of the variables included in study.

A glance at the Table 2 for discriminant coefficients of each of the variables shows i.e. factor E (-.424), factor Q3 ( -.294$)$, factor $\mathrm{L}(-.271), \mathrm{OH}(-.248)$ overtly hostile, factor C (-.230) (stable) are found to be associated with Group I (Alcoholic) while factor Q2 (.385), factor F (.376), powerful others (.362), covert hostility (.320), Internal scale (.266), factor Q1(.244), shows higher discriminant coefficients in group II (Non-alcoholics).

It was further seen that factor $\mathrm{O}(-.150)$ and factor $\mathrm{B}(-.142)$, factor $\mathrm{H}(-.051)$, factor $\mathrm{G}(-.031)$ are also found to be associated with Group I (Alcoholic) while factor M (.143), factor Q4 (.115), Chance Scale (.113), Factor A (.009) shows higher dicriminant coefficients in group II (Non-alcoholics).

The discriminant analysis approach gives an opportunity to rank factors that discriminate groups. These variables show high importance, so that present study results of analysis indicated alcoholic individuals are more emotionally stable, controlled, and suspicious. Alcoholics are independent minded and disregard to authority and they involve in overt acts of aggression to words peoples as compared to non-alcoholics.

Furthermore these Individuals are high on super ego, socially bold but value of this variable is very low. It means that alcoholic individual shows stronger super-ego and socially bold behavior under the influence of alcohol.

Regarding Group II, the results show that non-alcoholic individuals are enthusiastic, experimenting, self sufficient and covertly hostile. It means non- alcoholic individuals are covertly hostile i.e. they do not express hostile acts openly to the people. Alcoholics are more aggressive, hostile and troubled ones. Similar results have also been reported by (Baldwin and Randolph 1982, Rajendran and Cherian 1992, Michel 2003). Further non-alcoholic individuals are higher on internal locus of control and same time give importance to powerful others. Huckstadt (1997) also reports that non-alcoholics were high on internal locus of control than alcoholics.

Imaginative and chance scale has also shown some predictive power thus leading to a non-alcoholic value individuals. Though these variables do not have a high predictive power, nevertheless their importance cannot be ignored along with that tense and outgoing variable also show some importance.

It was also found that non-alcoholics are tender-minded and polished but they show low productive power so that these variables show some contribution in discrimination between two groups.

These results were also compared with those of t-test. It was seen that almost all the variables showed a similar trend of results in both the statistical techniques.

Additional information was collected through questionnaire exclusively prepared for this purpose. It was found that families of alcoholics have lower levels of family cohesion, expressiveness, independence, and intellectual orientation and higher levels of conflict as compared to non-alcoholic families. It suggests that a parent's continued drinking may be responsible for the disturbance of family life in an alcoholic home (Moos and Billings, 1982).

\section{References}

Abelsohn, DS and Van der Spuy, HI. (1978). The Age Variable in Alcoholism. Journal of Studies on Alcohol, 39(5), 800-808.

Baldwin, Joseph J., and Randolph, Daniel L. (1982). The Effect of Provocation on Aggression for Three Types of Alcohol use. Journal of Clinical Psychology, 38(2), 439-444.

Bendig, A. W. (1962). Factor Analytic Scales of Covert and Overt Hostility. Journal of Consulting Psychology, 26, 200.

Carmelo, A. Demoja. (1997). Scores on Locus of Control and Aggression for Drug Addicts, Users and Control. Psychological Reports, 80, 40-42.

Carson, Robert C, Butcher James N and Mineka Susan. (2000). Abnormal Psychology and Modern Life. Eleventh Edition, Allyn and Bacon: Boston, London.

Cattell, R.B. (1950). Personality: A Systematic Theoretical and Factual Study. McGraw Hill Book Co., New York.

Cattell, R. B. (1969). Administrator Manuals. Institute for Personality and Ability Testing, Champargn, Illinois. 
Huckstadt, Alicia. (1997). Locus of Control among Alcoholics, Recovering Alcoholics, and Non-alcoholics. Research in Nursing and Health, 10(1), 23-28.

Jellinek, E. M. (1960). The Disease Concept of Alcoholism. Hill house, New Jersey.

Jenny M. Eklund and Britt af Klinteberg. (2010). Alcohol Use and Patterns of Delinquent Behaviour in Male and Female Adolescents. Alcohol and Alcoholism, 44(6), 607-614.

Levenseen, H.S., \& Miller, J. (1976). Multidimensional LOC in Sociopolitical Activists of Conservative and Liberal Ideologies. Journal of Personality and Social Psychology, 33, 199-208.

Marchiori, E., Loschi, S., Marconi, P.L., \& Mioni, D. et al. (1999). Dependence, Locus of Control, Parental Bonding, and Personality Disorders: A Study of Alcoholics and Controls. Alcohol and Alcoholism, 34(3), 396-401.

Mello, N. K. (1972). Behavioral Studies of Alcoholism in The Biology of Alcoholism. (B. Kissin and H. Begleiter, eds.) Vol. 2, Physiology and Behaviour, 219-291 Plemn Press, New York.

Michel, S. McCloskey and Mitchell, E. Berman (2003). Alcohol Intoxication and Self- Aggressive Behavior. Journal of Abnormal Psychology, 112(2), 306-311.

Mills, Jon K (1992). Locus of Control Orientation of Obese Adolescent Girls and Children of Alcoholics in Outpatient Treatment. Psychological Reports, 70(3pt2), 1184-1186.

Mills, Jon K. (1991). A Comparison between Locus of Control in Inpatient Alcoholics and Children of Alcoholics. Journal of Studies on Alcohol, 36(3), 1-6.

Moos, R.H., \& Billings, A.G. (1982). Children of alcoholics during the recovery process: Alcoholic and matched control families. Addictive Behaviors, 7,155-163.

Obitz, Frederick W and Oziel, L Jerome. (1978). Change in General and Specific Perceived Locus of Control in Alcoholics as a Function of Treatment Exposure. International Journal of Addiction, 13(6), 995-1001.

Post, Phyllis., and Robinson, Bryan E. (1998). School- age Children of Alcoholics and Non-alcoholics: Their Anxiety, Self-esteem, and Locus of Control. Professional School Counselling, 1(5), 36-40.

Rajendran, R., and Cheriar, Raymol R. (1992). Alcoholism and Violent Behavior. Journal of Personality and Clinical Studies, 8(1-2), 39-42.

Renuka, Jena., Shukla, T.R., and Hemraj Pal. (1996). Drug Use in a Rural Community in Bihar: Some Psychological Correlates. Indian Journal of Psychiatry, 38(1), 43-46.

Robert, Young., Helen, Sweeting and Parick West. (2007). A Longitudinal Study of Alcohol Use and Antisocial Behavior in Young People. Alcohol and Alcoholism, 43(2), 204-214.

Rotter, J. B. (1966). Generalized Expectancies for Internal Versus External Control of Reinforcement. Psychology Monograph, 80(1), 609.

Russell, Daniel W., Booth, Brenda., Reed, David \& Laughlin, Philips R. (1997). Personality, Social Networks, and Perceived Social Support among Alcoholics: A Structural Equation Analysis. Journal of Personality, 65(3), 649-692.

Schumacher JA, Homish GG, Leonard KE, Quigley BM \& Kearns-Bodkin JN. (2008). Longitudinal Moderators of the Relationship between Excessive Drinking and Intimate Partner Violence in the Early Years of Marriage. Journal of Family Psychology, 22(6), 894-904.

Stacy, Alen W., Michael, D. New-comb and Peter, M. Bentler. (1991). Personality, Problem Drinking and Drunk Driving Mediating, Moderating and Direct Effect Models. Journal of Personality and Social Psychology, 60(5), 795-811.

Starrels, R. J. (1962). The Character Trait of the Alcoholic. Psychiatric Quarterly Supplement, 36(1), 14-34.

Suman, L N and Nagalakshmi, S. V. (1996). Family Dysfunction in Alcoholic Families. Indian Journal of Clinical Psychology, 23(1), 117-121.

Tivis, Laura J. Parsons, Oscar. a and Nixon, Sara J. (1998). Anger in an Inpatient Treatment Sample of Chronic Alcoholics. Clinical and Experimental research, 22(4), 902-907.

Ziherl S, Cebasek Travnik Z, Kores Plesnicar B, Tomori M, \& Zalar B. (2007). Trait Aggression and Hostility in recovered Alcoholics. Eur Addict Res, 13(2), 89-93.

Zungolo, Eilean. (1997). Locus of Control among Alcoholics, Recovering Alcoholics and Non- alcoholics. Commentary. Research in Nursing \& Health, 10(6), 399. 
Table 1. Means, Standard Deviations of Alcoholic and Non-alcoholic Groups on All the Measured Variables Along with their Statistical Significance of Difference between Means $(\mathrm{N}=200)$

\begin{tabular}{|c|c|c|c|c|c|c|c|}
\hline \multirow[t]{2}{*}{ Variable Name } & \multirow[t]{2}{*}{$\mathrm{Abb}$} & \multicolumn{2}{|c|}{$\begin{array}{l}\text { Alcoholics } \\
(n=100)\end{array}$} & \multicolumn{2}{|c|}{$\begin{array}{l}\text { Non-Alcoholic } \\
(n=100)\end{array}$} & \multirow[t]{2}{*}{ t-Value } & \multirow[t]{2}{*}{$P$} \\
\hline & & Mean & SD & Mean & SD & & \\
\hline Reserved / Outgoing & A & 7.82 & 2.09 & 8.08 & 2.13 & 0.87 & ns \\
\hline Dull / Bright & $\mathrm{B}$ & 4.18 & 1.49 & 3.95 & 1.07 & 1.26 & $\mathrm{~ns}$ \\
\hline Less Stable / Stable & $\mathrm{C}$ & 7.36 & 2.17 & 6.73 & 2.20 & 2.04 & $.05 *$ \\
\hline Humble / Assertive & $\mathrm{E}$ & 6.40 & 2.12 & 5.31 & 1.98 & 3.76 & $.01 * *$ \\
\hline Sober / Happy go Lucky & $\mathrm{F}$ & 6.04 & 2.09 & 6.97 & 1.86 & 3.32 & $.01 * *$ \\
\hline WeakerSuper Ego/Stronger super ego & G & 7.90 & 2.29 & 7.82 & 1.88 & 0.27 & ns \\
\hline Shy / Socially Bold & $\mathrm{H}$ & 7.08 & 2.16 & 6.93 & 2.51 & 0.45 & ns \\
\hline Tough minded / Tender minded & I & 5.18 & 1.90 & 5.40 & 2.35 & 0.73 & ns \\
\hline Trusting / Suspicious & $\mathrm{L}$ & 5.98 & 1.89 & 5.27 & 2.29 & 2.40 & $.05 *$ \\
\hline Practical / Imaginative & $\mathrm{M}$ & 5.64 & 1.78 & 5.99 & 2.12 & 1.26 & ns \\
\hline Genuine / polished & $\mathrm{N}$ & 4.80 & 1.97 & 4.90 & 2.46 & 0.32 & ns \\
\hline Self assured/ Apprehensive & $\mathrm{O}$ & 6.55 & 2.19 & 6.11 & 2.49 & 1.33 & ns \\
\hline Conservative / Experimenting & Q1 & 6.67 & 1.70 & 7.17 & 1.58 & 2.16 & $.05 *$ \\
\hline Group Dependent / Self Sufficient & Q2 & 4.97 & 2.32 & 6.11 & 2.41 & 3.41 & $.01 * *$ \\
\hline Undisciplined / Controlled & Q3 & 7.46 & 1.77 & 6.75 & 2.08 & 2.60 & $.01 * *$ \\
\hline Relaxed / Tense & Q4 & 5.14 & 2.39 & 5.48 & 2.34 & 1.02 & ns \\
\hline Internal Scale & IS & 31.07 & 3.58 & 32.24 & 3.43 & 2.36 & $.05 *$ \\
\hline Powerful Other & PS & 21.14 & 4.56 & 23.34 & 5.13 & 3.20 & $.01 * *$ \\
\hline Chance Scale & $\mathrm{CS}$ & 21.46 & 4.71 & 25.64 & 5.82 & 1.00 & $\mathrm{~ns}$ \\
\hline Covert Hostility & $\mathrm{CH}$ & 10.42 & 1.88 & 11.31 & 2.51 & 2.84 & $.01 * *$ \\
\hline Overt Hostility & $\mathrm{OH}$ & 7.54 & 1.91 & 6.93 & 2.01 & 2.20 & $.05^{*}$ \\
\hline
\end{tabular}

$* P<.05 \quad * * p<.01$ 
Table 2. Showing All the Measured Variables Along with the Discriminant Coefficients which are found to be Significant in Discriminating between Group I and Group II (N=200)

\begin{tabular}{|c|c|c|c|}
\hline \multicolumn{2}{|c|}{ Variables significant for Group I } & \multicolumn{2}{|c|}{ Variables significant for Group II } \\
\hline (Alcoholics) & $\begin{array}{l}\text { Discriminant } \\
\text { coefficient }\end{array}$ & (Non-alcoholics) & $\begin{array}{l}\text { Discriminant } \\
\text { coefficient }\end{array}$ \\
\hline Humble / Assertive (E) & -.424 & Group Dependent / Self Sufficient (Q2) & .385 \\
\hline Undisciplined / Controlled (Q3) & -.294 & Sober / Happy go Lucky (F) & .376 \\
\hline Trusting / Suspicious (L) & -.271 & Powerful Other (PS) & .362 \\
\hline Overt Hostility $(\mathrm{OH})$ & -.248 & Covert Hostility $(\mathrm{CH})$ & .320 \\
\hline Less Stable / Stable (C) & -.230 & Internal Scale ( IS) & .266 \\
\hline Self assured/ Apprehensive (O) & -.150 & Conservative / Experimenting (Q1) & .244 \\
\hline Dull / Bright (B) & -.142 & Practical / Imaginative (M) & .143 \\
\hline Shy / Socially Bold (H) & -.051 & Relaxed / Tense (Q4) & .115 \\
\hline \multirow{4}{*}{$\begin{array}{l}\text { Weaker Super Ego/Stronger } \\
\text { super ego }(\mathrm{G})\end{array}$} & -.031 & Chance Scale (CS) & .113 \\
\hline & & Reserved / Outgoing (A) & .099 \\
\hline & & Tough minded / Tender minded (I) & .082 \\
\hline & & Genuine / polished $(\mathrm{N})$ & .036 \\
\hline
\end{tabular}

Wilks' Lambda $=.716<.000$

Table 3. Classification Results

\begin{tabular}{|c|c|c|c|c|c|}
\hline & & \multirow[b]{2}{*}{ GROUP2 } & \multicolumn{2}{|c|}{ Predicted Group Membership } & \multirow[b]{2}{*}{ Total } \\
\hline & & & $\begin{array}{c}\text { Group I } \\
\text { (Alcoholic) }\end{array}$ & $\begin{array}{c}\text { Group II } \\
\text { (Non-alcoholics) }\end{array}$ & \\
\hline \multirow[t]{4}{*}{ Original } & \multirow[t]{2}{*}{ Count } & I & 74 & 26 & 100 \\
\hline & & II & 29 & 71 & 100 \\
\hline & \multirow[t]{2}{*}{$\%$} & I & 74.0 & 26.0 & 100.0 \\
\hline & & II & 29.0 & 71.0 & 100.0 \\
\hline
\end{tabular}

$72.5 \%$ of original grouped cases correctly classified. 